\title{
Bitte um Hilfe bei der Suche nach Werkhandschriften
}

Sehr geehrte Damen und Herren,

am Goethe- und Schiller-Archiv wurde im Jahr 1994 mit einer umfassenden Inventarisierung des Nachlasses von Goethe begonnen. Im Jahr 2000 erschien der erste Band des Inventars, in dem die Überlieferung von Goethes Gedichten verzeichnet ist. Weitere Bände sind in Vorbereitung. Als Ergänzung zu diesen Bänden sollen, gefördert von der Deutschen Forschungsgemeinschaft, auch die außerhalb des Archivs verwahrten Manuskripte der Werke Goethes erfaßt und für eine Präsentation im Internet aufbereitet werden.

Das Goethe-Museum Düsseldorf, das Schiller-Nationalmuseum und Deutsche Literaturarchiv Marbach am Neckar sowie das Freie Deutsche Hochstift und Frankfurter GoetheMuseum Frankfurt am Main haben bereits ihre Unterstützung zugesagt.

Die Mitarbeiter des Projekts bitten Sie um Hilfe bei der Auffindung bislang unbekannter oder für verschollen gehaltener Werkhandschriften. Für das gegenwärtige Vorhaben sind Manuskripte und zeitgenössische Abschriften von den poetischen, literatur- und kunsttheoretischen, naturwissenschaftlichen und autobiographischen Werken Goethes von Interesse.

Wir wären Ihnen sehr verbunden, wenn Sie unsere Arbeit unterstützen könnten. Ihre Angaben werden selbstverständlich vertraulich behandelt und ohne Ihre Zustimmung nicht weitergegeben.

Ihre Hinweise senden Sie bitte an:

Stiftung Weimarer Klassik und Kunstsammlungen

Goethe- und Schiller-Archiv

Dr. Judith Steiniger

Burgplatz 4

99423 Weimar

oder per e-mail an: (judith.steiniger@swkk.de).

Vielen Dank.

Silke Henke, Judith Steiniger 